\title{
An Adenosine Triphosphate-dependent Calcium Uptake Pump in Human Neutrophil Lysosomes
}

\author{
Mark S. Klempner \\ Division of Experimental Medicine, Department of Medicine, Tufts University School of Medicine, Boston, Massachusetts 02111
}

\begin{abstract}
Regulation of the cytosolic free calcium concentration is important to neutrophil function. In these studies, an ATPdependent calcium uptake pump has been identified in human neutrophil lysosomes. This energy-dependent $\mathrm{Ca}^{++}$uptake pump has a high affinity for $\mathrm{Ca}^{++}$(Michaelis constant $\left[K_{\mathrm{m}}\right]$ $\left.\mathrm{Ca}^{++}=107 \mathrm{nM}\right)$ and a maximum velocity $\left(V_{\max }\right)$ of $5.3 \mathrm{pmol} /$ mg of protein per min. ATP was the only nucleotide that supported $\mathrm{Ca}^{++}$uptake by lysosomes. The $K_{m}$ for ATP was $177 \mu \mathrm{M}$. ATP-dependent $\mathrm{Ca}^{++}$uptake by neutrophil lysosomes was temperature- and $\mathrm{pH}$-sensitive with optimal $\mathrm{Ca}^{++}$pump activity at $37^{\circ} \mathrm{C}$ and $\mathrm{pH}$ 7.0-7.5. $\mathrm{Mg}^{++}$was also essential for ATP-dependent $\mathrm{Ca}^{++}$uptake by lysosomes. Azide and antimycin $A$ had no effect on the energy-dependent uptake of $\mathrm{Ca}^{++}$by neutrophil lysosomes. The chemotactic peptide formyl-methionyl-leucyl-phenylalanine inhibited ATP-dependent $\mathrm{Ca}^{++}$accumulation by isolated lysosomes. Butoxycarbonyl-phenylalanine-leucine-phenylalanine-leucine-phenylalanine, a competitive antagonist of the chemotactic peptide, blocked this inhibitory effect. These studies demonstrate the presence of an ATPdependent $\mathrm{Ca}^{++}$uptake pump in human neutrophil lysosomes that functions at physiologic intracellular concentrations of $\mathrm{Ca}^{++}$, ATP, and $\mathrm{H}^{+}$and may be important to regulating neutrophil function by modulating cytosolic $\mathrm{Ca}^{++}$.
\end{abstract}

\section{Introduction}

The intracellular free $\mathrm{Ca}^{++}$concentration is widely recognized to influence stimulus-response coupling in numerous eukaryotic and prokaryotic cells. For polymorphonuclear leukocytes $(\mathrm{PMN}),{ }^{1}$ changes in cytoplasmic free $\mathrm{Ca}^{++}$concentration follow stimulation with ionophores and chemotactic peptides and have been implicated in control of PMN migration, phagocytosis, degranulation, and superoxide generation (1-5). $\mathrm{Ca}^{++}$is highly suited to regulate such functions because the concentration of the free ion in the cytosol is maintained at an

Address reprint requests to Dr. Klempner, Department of Medicine, Tufts-New England Medical Center, 171 Harrison Ave., Boston, MA 02111.

Received for publication 14 September 1984 and in revised form 19 February 1985.

1. Abbreviations used in this paper: BOC, butoxycarbonyl; ER, endoplasmic reticulum; FMLP, formyl-methionyl-leucyl-phenylalanine; PMN, polymorphonuclear leukocyte(s).

J. Clin. Invest.

(c) The American Society for Clinical Investigation, Inc.

0021-9738/85/07/0303/08 \$1.00

Volume 76, July 1985, 303-310 exceedingly low level $\left(10^{-7} \mathrm{M}\right.$, [3-6]) compared to other cations in the cytosol or compared to the $\mathrm{Ca}^{++}$concentration in extracellular fluid $\left(\sim 10^{-3} \mathrm{M}\right)$. Recent attention has focused on the presence of $\mathrm{Ca}^{++}$pumps in the plasma membranes of PMN and other cells that serve to maintain the low cytoplasmic free $\mathrm{Ca}^{++}$concentration by extruding $\mathrm{Ca}^{++}$(7-11). In many other cells, a major contribution to maintenance of the low cytosolic free $\mathrm{Ca}^{++}$concentration also comes from $\mathrm{Ca}^{++}$pumps that compartmentalize $\mathrm{Ca}^{++}$within intracellular organelles such as mitochondria and microsomes (12-14). PMN have few mitochondria and sparse endoplasmic reticulum and the major intracellular organelles within PMN are lysosomes. Therefore, studies were performed to determine whether these organelles might contribute to intracellular $\mathrm{Ca}^{++}$homeostasis by containing an energy-dependent $\mathrm{Ca}^{++}$pump that would serve to compartmentalize $\mathrm{Ca}^{++}$within lysosomes. This report demonstrates and characterizes, for the first time, an ATPdependent $\mathrm{Ca}^{++}$uptake pump in lysosomes of human PMN.

\section{Methods}

Chemicals. ATP, ADP, ITP, GTP, UTP, CTP, hexokinase, antimycin A, 4-methylumbelliferylsulfate, and 4-methylumbelliferone, formylmethionyl-leucyl-phenylalanine (FMLP), and ionophore A23187 were obtained from Sigma Chemical Co., St. Louis, MO; ${ }^{45} \mathrm{Ca}$ (as $\mathrm{CaCl}_{2}$ ) from New England Nuclear, Boston, MA; Hydrofluor from National Diagnostics Inc., Somerville, NJ; sodium azide from Mallinckrodt Chemical Co., St. Louis, MO; butoxycarbonyl(BOC)-phenylalanineleucine-phenylalanine-leucine-phenylalanine (BOC-Phe-Leu-Phe-LeuPhe) from Peninsula Laboratories, Inc., Belmont, CA; silicone oil (type SF1250) from General Electric Co., Waterford, NY; and Percoll from Pharmacia Fine Chemicals, Piscataway, NJ.

Isolation of lysosomes. Human PMN were isolated from healthy, adult volunteers by Ficoll-Hypaque gradient centrifugation and dextran sedimentation according to the method of Boyüm (15). Two methods were used to isolate lysosomes. In the first method, lysosomes were isolated from PMN after cell disruption by nitrogen cavitation and differential centrifugation as described in detail elsewhere (16). Briefly, PMN suspended in modified Hanks' balanced salt solution $\left(2 \times 10^{7} /\right.$ $\mathrm{ml}$, pH 7.4) containing $2.5 \mathrm{mM} \mathrm{MgCl}$ but without added $\mathrm{Ca}^{++}$were equilibrated at 350 psi of $\mathrm{N}_{2}$ for $20 \mathrm{~min}$ at $4^{\circ} \mathrm{C}$ in a cell disruption bomb (Artisan Industries, Waltham, MA). After release from the cavitation bomb, the suspension was collected into an EDTA (trisodium salt) solution so that the final concentration of EDTA was $2.5 \mathrm{mM}$. After an initial centrifugation $\left(1.0 \times 10^{4} \mathrm{~g} / \mathrm{min}, 4^{\circ} \mathrm{C}\right)$ to sediment undisrupted cells, nuclei, and mitochondria, the supernatant was centrifuged $\left(4.5 \times 10^{5} \mathrm{~g} / \mathrm{min}, 4^{\circ} \mathrm{C}\right)$ and the lysosome-containing pellet isolated. The undisturbed pellet was washed three times in ice-cold transport buffer composed of $\mathrm{KCl} 100 \mathrm{mM}, \mathrm{MgCl}_{2} 5 \mathrm{mM}$, Hepes 20

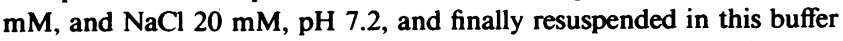
at a protein concentration of $100 \mu \mathrm{g} / \mathrm{ml}$. Protein was determined by the method of Bradford (17) with bovine serum albumin as standard. In some experiments, $\mathrm{MgCl}_{2}$ was omitted from the transport buffer.

In separate experiments, PMN lysosomes were isolated and frac- 
tionated according to the method of Borregaard et al. (18), modified as follows. PMN, suspended in ice-cold "relaxation buffer" containing $\mathrm{KCl} 100 \mathrm{mM}$, NaCl $3 \mathrm{mM}$, ATP $1 \mathrm{mM}, \mathrm{MgCl}_{2} 3.5 \mathrm{mM}$, piperazine$N$ - $N^{\prime}$-bis 2-ethane-sulfonic acid $10 \mathrm{mM}, \mathrm{pH} 7.4$, were disrupted by $\mathrm{N}_{2}$ cavitation (350 psi, $20 \mathrm{~min} 4^{\circ} \mathrm{C}$ ) and the cavitate was collected into EGTA (final concentration, $1.25 \mathrm{mM}$ ). After removal of nuclei and unbroken cells by centrifugation at $500 \mathrm{~g}$ for $10 \mathrm{~min}$ at $4^{\circ} \mathrm{C}$, the supernatant was decanted and centrifuged at $15,000 \mathrm{~g}$ for $20 \mathrm{~min}$ at $4^{\circ} \mathrm{C}$ to sediment the lysosome-containing pellet. This fraction was resuspended in "relaxation buffer" and loaded onto discontinuous Percoll gradients prepared as described in reference 18. Two distinct bands ( $\alpha$ and $\beta$, in order of decreasing density) were identified after centrifugation of the loaded discontinuous Percoll gradients at 48,000 $g$ for $15 \mathrm{~min}$ at $4^{\circ} \mathrm{C}$. No other visible bands were observed in these gradients. Material forming the $\alpha$-band, previously identified as the azurophil granules (18), and $\beta$-band (specific granules contaminated by $\sim 10 \%$ of the azurophil granules) were isolated by aspiration. In some preparations, Percoll was removed from these fractions by centrifugation at $170,000 \mathrm{~g}$ for $15 \mathrm{~min}$, and the lysosomes, which layered on a hard-packed pellet of Percoll, were aspirated and suspended in transport buffer at a final protein concentration of $100 \mu \mathrm{g} / \mathrm{ml}$. Sulfatase $\mathrm{C}$ activity, a marker for endoplasmic reticulum, was measured in the cavitate, the resuspended lysosome suspension, and the $\alpha$ - and $\beta$-bands from the Percoll gradient according to the method of Canonico et al. (19). The assay of sulfatase $C$ activity depends on the fluorometric measurement of the conversion of 4-methylumbelliferylsulfate to 4methylumbelliferone under conditions which inhibit sulfatase $A$ and sulfatase B activity (19). A sham Percoll gradient was run in parallel with the lysosome-containing gradient, and sulfatase $\mathrm{C}$ activity was measured in Percoll fractions of comparable density to the $\alpha$ - and $\beta$ bands.

Calcium uptake studies. Calcium uptake by lysosomes was measured in the transport medium supplemented with varying concentrations of ATP and $\mathrm{CaCl}_{2}$ as follows. Lysosomes suspended in medium at 100 $\mu \mathrm{g}$ of protein $/ \mathrm{ml}$ were prewarmed to $37^{\circ} \mathrm{C}$ for $5-10 \mathrm{~min}$ and agitated, and the reaction was started by the addition of prewarmed $\mathrm{CaCl}_{2}$ (usually $100 \mu \mathrm{M}$ containing $1 \mu \mathrm{Ci} / \mathrm{ml}$ of ${ }^{45} \mathrm{Ca}$ ) and prewarmed ATP solution (final concentration usually $1 \mathrm{mM}$ ). The $\mathrm{pH}$ of all solutions was preadjusted to 7.2 except where otherwise noted. The suspension was agitated and incubated at $37^{\circ} \mathrm{C}$. At intervals, $1.0-\mathrm{ml}$ aliquots were removed and layered over $0.5 \mathrm{ml}$ of silicone oil (type SF1250) in microcentrifuge tubes (Beckman Instruments, Inc., Fullerton, CA). Lysosomes were rapidly sedimented from the medium by centrifugation at $12,000 \mathrm{~g}$ for $3 \mathrm{~min}$ at room temperature as previously described (20). A $10-\mu l$ aliquot of the supernatant was removed from each sample, placed in $10 \mathrm{ml}$ of scintillation fluid (Hydrofluor), and counted for ${ }^{45} \mathrm{Ca}$ radioactivity in a liquid scintillation counter (Beckman Instruments, Inc.). The remainder of the supernatant and the top 0.3 $\mathrm{ml}$ of silicone oil were aspirated and discarded, and the entire lysosome pellet was harvested by cutting off the pellet containing portion of the microcentrifuge tube. The lysosome pellet was placed in $10 \mathrm{ml}$ of liquid scintillation fluid and counted for ${ }^{45} \mathrm{Ca}$ radioactivity. In that initial experiments demonstrated that $\mathrm{Ca}^{++}$uptake by lysosomes did not occur in the absence of ATP (see Fig. 1), $\mathrm{Ca}^{++}$uptake rates are expressed as nanomoles of $\mathrm{Ca}^{++}$per milligram of protein per minute after subtracting the ${ }^{45} \mathrm{Ca}$ radioactivity in the lysosome pellet in the absence of ATP.

Because endoplasmic reticulum (ER) and mitochondria both contain ATP-dependent $\mathrm{Ca}^{++}$uptake pumps (12-14) and contaminate the lysosome suspension before Percoll gradient centrifugation (16), additional studies were done to determine whether ATP-dependent $\mathrm{Ca}^{++}$ uptake by the unfractionated lysosomes could be attributed to these organelles. Sedimentation of ER through the silicone oil layer was monitored by measurement of NADH-oxidoreductase activity (21) in the lysosome suspension and in the supernatant (above the oil layer) and pellet of a lysosome suspension centrifuged through silicone oil. In parallel, ATP-dependent $\mathrm{Ca}^{++}$uptake was measured in the lysosome suspension and in the lysosome pellet obtained after sedimentation through silicone oil. Because Percoll interfered with the measurement of NADH-oxidoreductase activity, in experiments that utilized Percoll gradient-fractionated lysosomes, sulfatase $\mathrm{C}$ activity was measured in the various fractions as described above. The effects of sodium azide $(5 \mathrm{mM})$ and antimycin $\mathrm{A}\left(5 \times 10^{-7} \mathrm{M}\right)$, which completely inhibit the mitochondrial electron transport chain and $\mathrm{Ca}^{++}$uptake pump activity $(12,22)$, on ATP-dependent $\mathrm{Ca}^{++}$uptake by the lysosome suspension were also determined.

The free $\mathrm{Ca}^{++}$concentration of solutions in the presence of ATP and EGTA was calculated from the contaminating $\mathrm{Ca}^{++}$, measured with a $\mathrm{Ca}^{++}$sensitive electrode (model F2112; Radiometer, Inc., Copenhagen, Denmark), plus the amount of $\mathrm{Ca}^{++}$added, using the computer program of Perrin and Sayce (23) with the following logarithmic association constants for metals and $\mathrm{H}^{+}$to EGTA: $\mathrm{H}^{+}$to EGTA $^{4-}, 9.46 ; \mathrm{H}^{+}$to $\mathrm{H} \mathrm{EGTA}^{3-}, 8.85 ; \mathrm{H}^{+}$to $\mathrm{H}_{2} \mathrm{EGTA}^{2-}, 2.68 ; \mathrm{H}^{+}$ to $\mathrm{H}_{3} \mathrm{EGTA}^{1-}, 2.0 ; \mathrm{Ca}^{++}$to EGTA ${ }^{4-}, 11.0 ; \mathrm{Ca}^{++}$to $\mathrm{H} \mathrm{EGTA}^{3-}, 5.33$; $\mathrm{Mg}^{++}$to EGTA ${ }^{4-}, 5.21 ; \mathrm{Mg}^{++}$to $\mathrm{H}$ EGTA ${ }^{3-}, 3.37$. Kinetic parameters (Michaelis constant $\left[K_{\mathrm{m}}\right]$ and maximum velocity $\left[V_{\mathrm{max}}\right]$ ) were determined from double reciprocal plots drawn by computer-assisted least squares analysis. In addition to characterizing the kinetic parameters of $\mathrm{Ca}^{++}$ uptake by PMN lysosomes as to $\left[\mathrm{Ca}^{++}\right]$and [ATP], the effects of varying temperature, $\mathrm{pH},\left[\mathrm{Mg}^{++}\right]$, and nucleotides were also examined.

Effect of FMLP on ATP-dependent $\mathrm{Ca}^{++}$accumulation by lysosomes. Lysosomes suspended in transport medium at $100 \mu \mathrm{g}$ of protein $/ \mathrm{ml}$ were warmed to $37^{\circ} \mathrm{C}$ to $5-10 \mathrm{~min}$ in the presence and absence of varying concentrations of FMLP. Calcium uptake was initiated by the addition of prewarmed $\mathrm{CaCl}_{2}$ (containing ${ }^{45} \mathrm{Ca}$ ) and $\mathrm{ATP}$ as described for the standard $\mathrm{Ca}^{++}$uptake studies. The effect of the chemotactic peptide antagonist BOC-Phe-Leu-Phe-Leu-Phe, alone or in combination with FMLP, was also assessed. Lysosomes were warmed to $37^{\circ} \mathrm{C}$ for 5 $\mathrm{min}$ in the presence and absence of BOC-Phe-Leu-Phe-Leu-Phe $\left(10^{-5}\right)$ followed by the addition of prewarmed transport medium or FMLP $\left(10^{-10}\right)$. After $5 \mathrm{~min}$ at $37^{\circ} \mathrm{C}, \mathrm{Ca}^{++}$uptake was initiated by adding prewarmed $\mathrm{CaCl}_{2}$ and ATP.

To determine whether $\mathrm{Ca}^{++}$leakage from the lysosomes was affected by FMLP treatment, lysosomes were allowed to accumulate $\mathrm{CaCl}_{2}$ (containing ${ }^{45} \mathrm{Ca}$ ) for $10 \mathrm{~min}$ at $37^{\circ} \mathrm{C}$ in the presence of $\mathrm{ATP}$ (standard uptake assay). At the plateau of $\mathrm{Ca}^{++}$uptake, prewarmed EGTA (2.5 mM, pH 7.2) with or without FMLP $\left(10^{-10} \mathrm{M}\right)$ was added to the lysosome suspension and lysosome-associated ${ }^{45} \mathrm{Ca}^{++}$was determined at intervals.

Additional experiments were performed to determine whether FMLP accelerated the efflux of $\mathrm{Ca}^{++}$from the lysosomes against a concentration gradient. At the plateau of active $\mathrm{Ca}^{++}$uptake by the lysosomes, ATP was effectively removed from the medium by the addition of glucose $(5 \mathrm{mM})$ and hexokinase $(20 \mathrm{U} / \mathrm{ml})$ (24). At intervals, the amount of ${ }^{45} \mathrm{Ca}$ retained by the lysosomes in the presence and absence of FMLP $\left(10^{-10} \mathrm{M}\right)$ was determined.

\section{Results}

The uptake of $\mathrm{Ca}^{++}$by isolated human PMN lysosomes in the presence and absence of ATP $(1 \mathrm{mM})$ is shown in Fig. 1. In the absence of ATP, $0.4 \pm 0.1 \mathrm{nmol}$ of $\mathrm{Ca}^{++} / \mathrm{mg}$ of protein was associated with the lysosome pellet during the first $2-5 \mathrm{~min}$ of incubation. There was no further association of $\mathrm{Ca}^{++}$with the lysosome pellet during the $30-\mathrm{min}$ incubation. In the presence of ATP and $\mathrm{MgCl}_{2}(5 \mathrm{mM})$, there was a rapid uptake of $\mathrm{Ca}^{++}$ by the lysosomes which was almost linear over the first $5 \mathrm{~min}$. $\mathrm{Ca}^{++}$uptake continued at a slower rate over the next $5 \mathrm{~min}$. As shown in Fig. 2, ATP-dependent $\mathrm{Ca}^{++}$uptake by lysosomes required $\mathrm{Mg}^{++}$. In the absence of $\mathrm{Mg}^{++}, \mathrm{Ca}^{++}$uptake by the lysosomes was similar to $\mathrm{Ca}^{++}$uptake in the absence of ATP. That the uptake of $\mathrm{Ca}^{++}$by lysosomes in the presence of ATP 


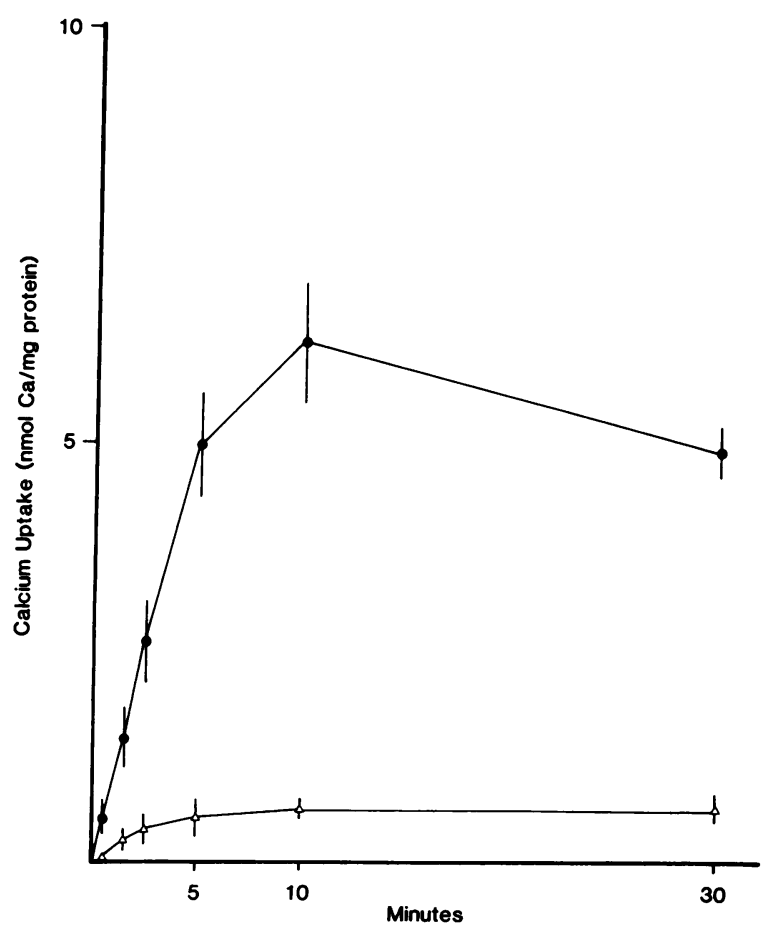

Figure 1. Ca uptake by human neutrophil lysosomes. Lysosomes were suspended in transport buffer $(\mathrm{KCl} 100 \mathrm{mM}, \mathrm{NaCl} 20 \mathrm{mM}$, $\mathrm{MgCl}_{2} 5 \mathrm{mM}$, Hepes $20 \mathrm{mM}$, pH 7.2) containing $100 \mu \mathrm{M} \mathrm{CaCl}_{2}$ with $1 \mu \mathrm{Ci} / \mathrm{ml}$ of ${ }^{45} \mathrm{Ca}$. Ca uptake was measured at $37^{\circ} \mathrm{C}$ in the presence $(\bullet)$ and absence $(\Delta)$ of ATP $(1 \mathrm{mM})$. Results are the mean \pm SEM of seven experiments.

and $\mathrm{MgCl}_{2}$ was against an electrochemical gradient is also shown in Fig. 2. Addition of the $\mathrm{Ca}^{++}$ionophore A23187 (5 $\mu \mathrm{M})$ after $5 \mathrm{~min}$ of $\mathrm{Ca}^{++}$uptake by the lysosomes caused a rapid release of $\mathrm{Ca}^{++}$to near basal levels.

To examine further whether the ATP-dependent uptake of $\mathrm{Ca}^{++}$could be attributed to the lysosomes and not to the small amount of contaminating ER, the ER marker enzyme NADHoxidoreductase was measured in the organelle suspension before and after passage over silicone oil. Almost all of the ER was retained above the silicone oil layer. In four separate experiments, the specific activity of NADH-oxidoreductase (expressed as micromoles of $\mathrm{NADH}$ oxidized per milligram of protein per minute) was $2.4 \pm 0.1,11.3 \pm 1.7$, and $1.1 \pm 0.2$ in the lysosome suspension, layer above the silicone oil, and lysosome pellet below the silicone oil layer, respectively. Of the total protein in the lysosome suspension, $10.6 \pm 2.5 \%$ was retained above the silicone oil layer $(n=4)$. In contrast, depletion of contaminating ER from the lysosome suspension by centrifugation through silicone oil had no significant effect on ATP-dependent $\mathrm{Ca}^{++}$uptake activity $(1.20 \pm 0.15 \mathrm{nmol}$ of $\mathrm{Ca}^{++} / \mathrm{mg}$ of protein per min in the lysosome suspension vs. $1.19 \pm 0.19 \mathrm{nmol}$ of $\mathrm{Ca}^{++} / \mathrm{mg}$ of protein per min in lysosomes obtained after centrifugation through silicone oil; $n=2$ ).

The effects of two inhibitors of mitochondrial respiration and ion transport on the energy-dependent uptake of $\mathrm{Ca}^{++}$by the lysosomes were also examined. Sodium azide $(5 \mathrm{mM})$ had no effect on ATP-dependent $\mathrm{Ca}^{++}$uptake by human PMN lysosomes $\left(0.89 \pm 0.17 \mathrm{nmol}\right.$ of $\mathrm{Ca}^{++} / \mathrm{mg}$ of protein per min

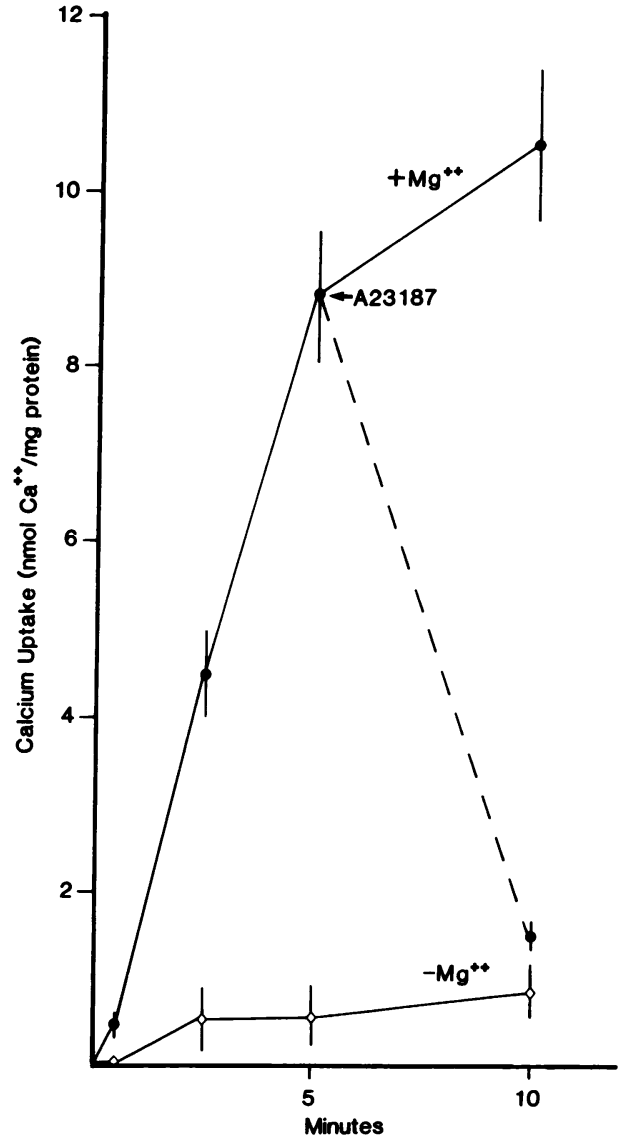

Figure 2. $\mathrm{Mg}^{++}$requirement and effect of $\mathrm{A} 23187$ on Ca uptake by lysosomes. ATP (1 mM)-dependent Ca uptake by lysosomes was measured in the same transport medium as Fig. 1 with (-) and without $(\diamond)$ added $\mathrm{MgCl}_{2}(5 \mathrm{mM})$. At $5 \mathrm{~min}$, A23187 $(5 \mu \mathrm{M})$ was added to the complete incubation mixture (-.-.-). Results are the mean \pm SEM of four experiments.

without azide vs. $0.81 \pm 0.21 \mathrm{nmol}$ of $\mathrm{Ca}^{++} / \mathrm{mg}$ of protein per min with azide; $n=2)$. Antimycin $A\left(5 \times 10^{-7} \mathrm{M}\right)$, which inhibits mitochondrial electron transfer at a different site than sodium azide, also had no effect on ATP-dependent uptake of $\mathrm{Ca}^{++}$by the lysosomes $\left(0.82 \pm 0.22 \mathrm{nmol}\right.$ of $\mathrm{Ca}^{++} / \mathrm{mg}$ of protein per min without antimycin A vs. $0.82 \pm 0.16 \mathrm{nmol} \mathrm{of} \mathrm{Ca}^{++} / \mathrm{mg}$ of protein per min with antimycin $\mathrm{A}$ ).

A second method was also used to isolate PMN lysosomes which permits fractionation of the lysosomes into azurophil ( $\alpha$-band) and specific ( $\beta$-band) granules, removes any contaminating mitochondrial marker enzyme (18), and, as shown below, removes contaminating ER. As previously reported for the mitochondrial marker cytochrome $c$ oxidase (18), no monamine oxidase activity was detected in the Percoll gradient fractions ( $n=3$, data not shown). While the activity of the ER marker enzyme, sulfatase $C$, was low in comparison to cells that synthesize protein (19), it was detected in the cavitate of the PMN suspension and in the resuspended, unfractionated lysosome suspension. No latency for the sulfatase $\mathrm{C}$ activity could be detected in either the cavitate or the lysosome suspension. The whole cell cavitate from $1 \times 10^{9}$ cells converted $75.2 \pm 3.6 \mathrm{nmol}$ of 4-methylumbelliferylsulfate to 4-methylum- 
belliferone after $20 \mathrm{~min}$ of incubation. The unfractionated lysosome suspension contained $29.9 \%$ of the whole cell cavitate sulfatase $C$ activity ( $22.5 \mathrm{nmol}$ of 4-methylumbelliferone generated after 20 min of incubation). By using glucose-6-phosphatase activity as another ER marker enzyme, we previously found that the lysosome suspension contained $20.0 \%$ of the cell cavitate activity (16). In contrast, both the azurophil ( $\alpha$ band) and specific ( $\beta$-band) lysosomes recovered from the discontinuous Percoll gradients contained no detectable sulfatase $C$ activity $(n=3)$. Sulfatase $C$ activity was not inhibited by the presence of Percoll and the fluorescent signal from 4methylumbelliferone was actually increased from 10 to $16 \%$ in its presence. Because the total sulfatase $\mathrm{C}$ activity in the cell cavitate and lysosome suspension was low and no other bands were visible in the Percoll gradients $(n=3)(18)$, the locale of the ER could not be determined with certainty and ER could not be recovered from the gradients.

Unlike the complete removal of sulfatase $\mathrm{C}$ activity from the alpha and beta Percoll gradient fractions, ATP-dependent $\mathrm{Ca}^{++}$uptake was clearly present in both lysosome fractions. In a representative experiment, the ATP-dependent $\mathrm{Ca}^{++}$ uptake activity in the unfractionated lysosome suspension was $0.72 \mathrm{nmol}$ of $\mathrm{Ca}^{++} / \mathrm{mg}$ of protein per min, $1.67 \mathrm{nmol} \mathrm{of} \mathrm{Ca}^{++} /$ $\mathrm{mg}$ of protein per min in the azurophil granules, and 1.16 nmol of $\mathrm{Ca}^{++} / \mathrm{mg}$ of protein per min in the specific granules. While there was invariably energy-dependent $\mathrm{Ca}^{++}$uptake by both azurophil and specific granules $(n=4)$, the specific activity for $\mathrm{Ca}^{++}$uptake was variable largely owing to incomplete removal of Percoll from the gradient-fractionated lysosomes. Incubation of unfractionated lysosomes with Percoll had no direct effect on $\mathrm{Ca}^{++}$uptake activity (data not shown), however, residual Percoll in the gradient-fractionated lysosomes interfered with the complete recovery of lysosomes after centrifugation through silicone oil.

The kinetic parameters for $\mathrm{Ca}^{++}$uptake by unfractionated lysosomes at various free $\mathrm{Ca}^{++}$concentrations are shown in Fig. 3. The $K_{\mathrm{m}}$ for $\mathrm{Ca}^{++}$was $107 \mathrm{nM}$ and the $V_{\max }$ was 5.3 pmol of $\mathrm{Ca}^{++} / \mathrm{mg}$ of protein per min.

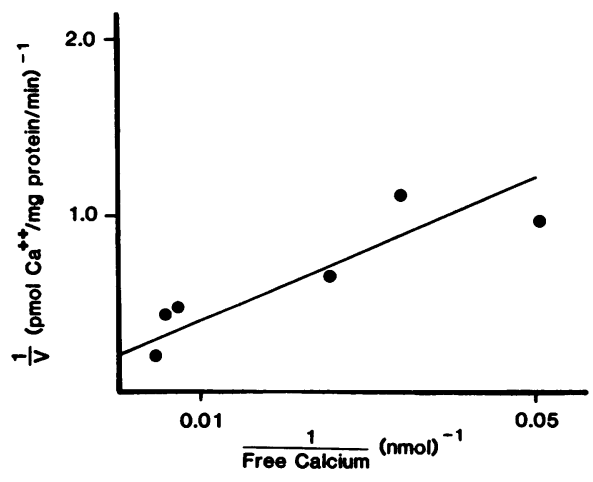

Figure 3. Lineweaver-Burk plot of $\mathrm{Ca}$ uptake by lysosomes at various free Ca concentrations. Free Ca concentrations $(20-400 \mathrm{nM})$ in transport buffer (see Fig. 1) were adjusted by the addition of various concentrations of EGTA according to the measurements and calculations described in the text. Results are the mean of four experiments. $K_{\mathrm{m}}=107 \mathrm{nM} ; V_{\max }=5.3 \mathrm{pM}$.

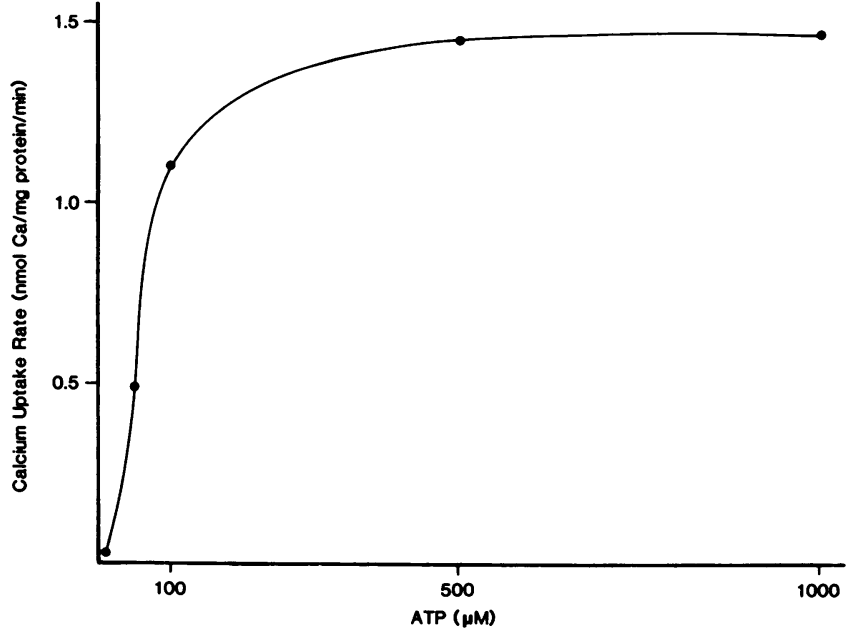

Figure 4. Ca uptake rate by lysosomes at various ATP concentrations. Uptake of $\mathrm{Ca}^{++}$was measured in transport buffer (Fig. 1) supplemented with ATP: $25,50,100,500$, and $1000 \mu \mathrm{M}$. Results are the mean of three experiments.

The $\mathrm{Ca}^{++}$uptake rate by lysosomes at various ATP concentrations is shown in Fig. 4. The double reciprocal plot of these data revealed a $K_{\mathrm{m}}$ for ATP of $177 \mu \mathrm{M}$.

As shown in Table I, the nucleotide specificity for support of $\mathrm{Ca}^{++}$uptake by lysosomes was exclusive for ATP. None of the other nucleotides (ADP, UTP, CTP, GTP, or ITP) resulted in $\mathrm{Ca}^{++}$uptake $>2 \%$ of that supported by ATP.

Temperature and $\mathrm{pH}$ had profound effects on the ATPdependent $\mathrm{Ca}^{++}$uptake by lysosomes. At $4^{\circ} \mathrm{C}$, no $\mathrm{Ca}^{++}$uptake was detectable and at $25^{\circ} \mathrm{C}, \mathrm{Ca}^{++}$uptake was $41 \%$ of the uptake observed at $37^{\circ} \mathrm{C}$. Fig. 5 shows the effects of $\mathrm{pH}$ on $\mathrm{Ca}^{++}$uptake by lysosomes. The optimal $\mathrm{pH}$ for $\mathrm{Ca}^{++}$uptake was between 7.0 and 7.5. At very acidic $\mathrm{pH}(5.5), \mathrm{Ca}^{++}$pump activity was $29 \%$ of maximal and $72 \%$ of maximal activity at very alkaline $\mathrm{pH}(\mathbf{8 . 0 )}$.

FMLP inhibition of ATP-dependent $\mathrm{Ca}^{++}$accumulation by lysosomes. FMLP inhibited ATP-dependent $\mathrm{Ca}^{++}$accumulation

Table I. Nucleotide Specificity for Calcium Uptake by Human Neutrophil Lysosomes

\begin{tabular}{lc}
\hline Nucleotide & \% activity \\
\hline ATP & $100.0 \pm 6.6$ \\
ADP & $0 \pm 0$ \\
UTP & $1.7 \pm 1.2$ \\
CTP & $1.0 \pm 0.4$ \\
GTP & $0 \pm 0$ \\
ITP & $0 \pm 0$
\end{tabular}

Incubation conditions and measurements of $\mathrm{Ca}^{++}$uptake were as described in Methods. All nucleotides were present at a final concentration of $1 \mathrm{mM}$. Activity is expressed as the percentage (mean \pm SEM) of activity in the presence of ATP from two separate experiments, each run in duplicate. 


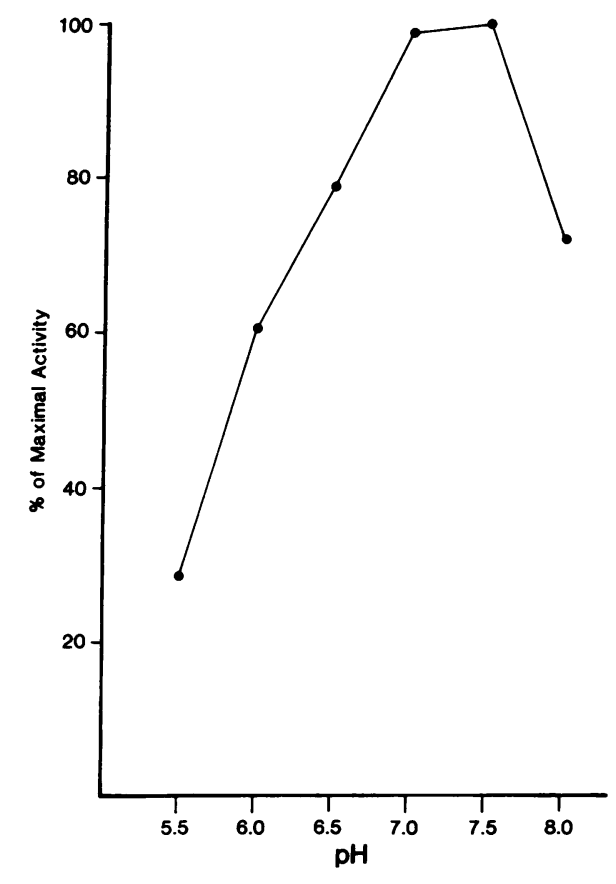

Figure 5. Effect of pH on ATP-dependent Ca uptake by lysosomes. Incubation conditions were as described in Fig. 1, with the $\mathrm{pH}$ adjusted at $37^{\circ} \mathrm{C}$ as indicated. Results are the mean of three experiments.

by lysosomes in a dose-dependent fashion (Fig. 6). Lysosomal accumulation of $\mathrm{Ca}^{++}$was inhibited to a similar degree whether lysosomes were treated with FMLP for 5 or $10 \mathrm{~min}$. There was no effect of FMLP $\left(10^{-6} \mathrm{M}\right)$ on the amount of ${ }^{45} \mathrm{Ca}^{++}$ associated with the lysosome pellet in the absence of ATP

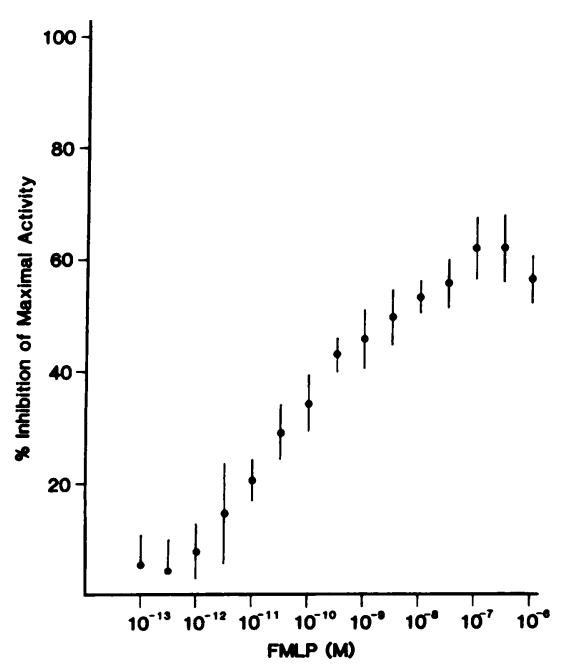

Figure 6. Effect of FMLP on ATP-dependent $\mathrm{Ca}^{++}$accumulation by lysosomes. Lysosomes in transport buffer were incubated for 5-10 min at $37^{\circ} \mathrm{C}$ in the absence and presence of varying concentrations of FMLP. Uptake of $\mathrm{Ca}^{++}$was then measured as in Fig. 1. Results are the mean \pm SEM of three to nine separate experiments.
Table II. BOC-Phe-Leu-Phe-Leu-Phe Blocks the Inhibitory Effect of FMLP on ATP-dependent $\mathrm{Ca}^{++}$Uptake by Lysosomes

\begin{tabular}{ll}
\hline Addition & Activity \\
\hline & nmol of $\mathrm{Ca}^{++} \mathrm{mg}$ of protein per min \\
None & $1.04 \pm 0.07$ \\
FMLP $\left(10^{-10} \mathrm{M}\right)$ & $0.49 \pm 0.10$ \\
BOC-Phe-Leu-Phe-Leu-Phe & \\
$\quad\left(10^{-5} \mathrm{M}\right)$ & $1.08 \pm 0.17$ \\
BOC-Phe-Leu-Phe-Leu-Phe & \\
$\left(10^{-5} \mathrm{M}\right)+$ FMLP $\left(10^{-10} \mathrm{M}\right)$ & $1.15 \pm 0.14$ \\
\hline
\end{tabular}

Incubations and $\mathrm{Ca}^{++}$uptake were performed as described in Methods. Results are the mean \pm SEM of three experiments, each run in duplicate.

$\left(0.26 \pm 0.08 \mathrm{nmol}\right.$ of $\mathrm{Ca}^{++} / \mathrm{mg}$ of protein vs. $0.23 \pm 0.10 \mathrm{nmol}$ of $\mathrm{Ca}^{++} / \mathrm{mg}$ of protein in the absence and presence of FMLP, respectively, after a 5 -min incubation, $n=9$ ). Table II shows the ability of BOC-Phe-Leu-Phe-Leu-Phe to block the inhibitory effect of FMLP on ATP-dependent $\mathrm{Ca}^{++}$accumulation by the lysosomes. The antagonist alone had no significant effect on accumulation of $\mathrm{Ca}^{++}$by lysosomes.

As shown in Fig. 7, the addition of sufficient EGTA to chelate virtually all the extralysosomal $\mathrm{Ca}^{++}\left(\left[\mathrm{Ca}^{++}\right]_{0}<1 \mathrm{nM}\right)$ at the plateau of ATP-dependent $\mathrm{Ca}^{++}$uptake, promoted an efflux of $\mathrm{Ca}^{++}$down its concentration gradient. FMLP $\left(10^{-10}\right.$ M) did not enhance the efflux of $\mathrm{Ca}^{++}$from the lysosomes, indicating that the effect of FMLP was not to render the lysosomes relatively more permeable to calcium.

Fig. 8 shows the effect of FMLP on $\mathrm{Ca}^{++}$efflux from the

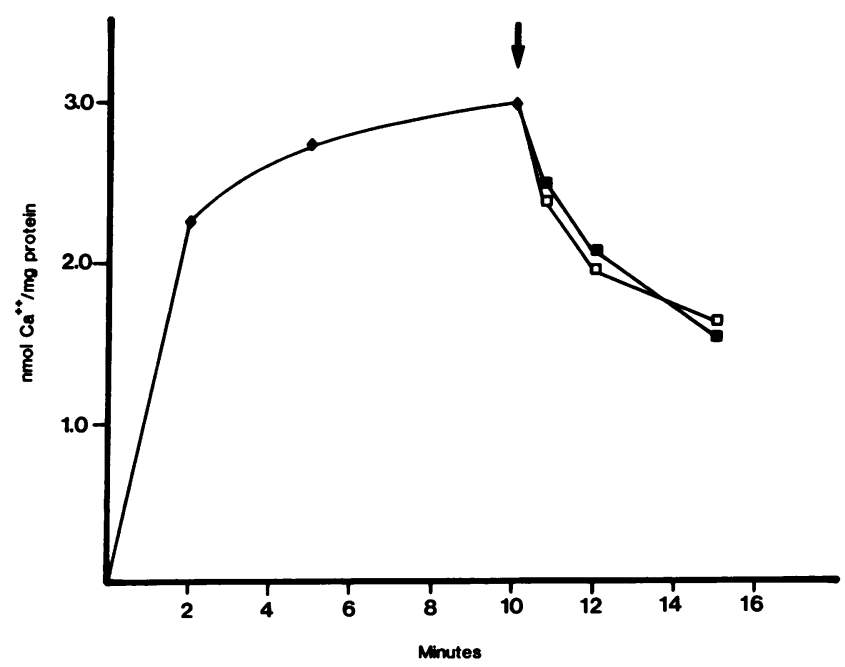

Figure 7. Effect of FMLP on lysosomal permeability to $\mathrm{Ca}^{++}$. At the plateau of $\mathrm{Ca}^{++}$uptake by lysosomes (10 min, arrow), EGTA (2.5 $\mathrm{mM}, \mathrm{pH}$ 7.2) was added with (口) or without (๘) FMLP $\left(10^{-10} \mathrm{M}\right)$. Under these conditions, extralysosomal $\left[\mathrm{Ca}^{++}\right]$was reduced to $<1.0$ nM. At intervals, lysosome-associated ${ }^{45} \mathrm{Ca}^{++}$was measured. Results are the mean of three experiments. 


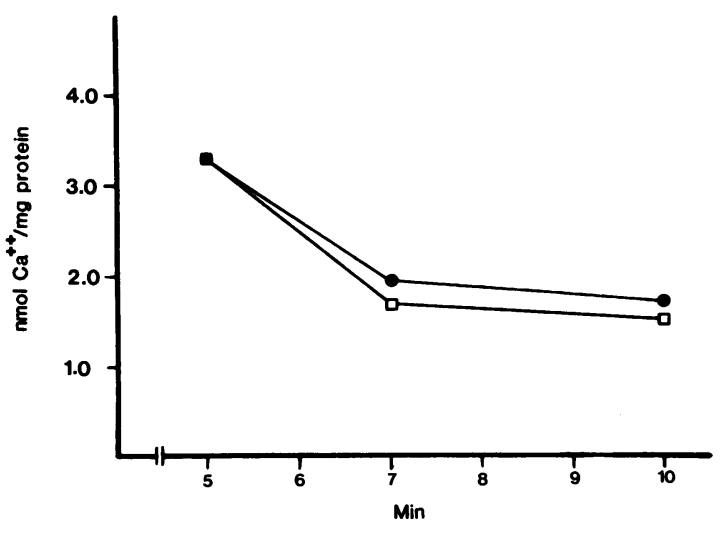

Figure 8. Effect of FMLP on efflux of calcium from lysosomes. After 5 min of active $\mathrm{Ca}^{++}$uptake by lysosomes under standard assay conditions (see Fig. 1), the concentration of ATP was effectively reduced by the addition of glucose $(5 \mathrm{mM})$ and hexokinase $(20 \mathrm{U} /$ $\mathrm{ml}$ ) with ( $\square$ ) or without (๑) FMLP $\left(10^{-10} \mathrm{M}\right)$. Lysosome-associated ${ }^{45} \mathrm{Ca}^{++}$was measured 2 and $5 \mathrm{~min}$ after the additions. Results are the mean of three experiments.

lysosomes when the extralysosomal $\mathrm{Ca}^{++}$concentration was not changed. FMLP $\left(10^{-10} \mathrm{M}\right)$ added at the plateau of $\mathrm{Ca}^{++}$ uptake and after lowering the ATP concentration by the addition of glucose and hexokinase did not increase $\mathrm{Ca}^{++}$ efflux from the lysosomes, indicating that the inhibition of $\mathrm{Ca}^{++}$accumulation by lysosomes treated with FMLP is the result of inhibited $\mathrm{Ca}^{++}$influx.

\section{Discussion}

This report describes the presence of an ATP-dependent $\mathrm{Ca}^{++}$ uptake pump in isolated human PMN lysosomes that pumps $\mathrm{Ca}^{++}$against an electrochemical gradient, requires $\mathrm{Mg}^{++}$, and operates at $\mathrm{Ca}^{++}, \mathrm{ATP}$, and $\mathrm{H}^{+}$concentrations relevant to the cytoplasmic environment. That the $\mathrm{Ca}^{++}$uptake pump activity is attributable to lysosomes and not to contaminating subcellular organelles is supported by several lines of evidence. First is the purity of the lysosome fraction obtained by disrupting PMN by nitrogen cavitation and separating organelles by differential centrifugation. By using ouabain inhibitable $\mathrm{Na}^{+}-\mathrm{K}^{+}$ATPase and 5-nucleotidase activities as markers for the plasma membrane, we have previously shown that this preparation of lysosomes is entirely free of contaminating plasma membrane vesicles (16). Moreover, plasma membrane vesicles, which are less dense than ER (16), do not sediment through silicone oil (type SF1250). Mitochondria, which have an active $\mathrm{Ca}^{++}$ uptake pump, are sparse in PMN and none are seen in electron micrographs of the lysosome preparation. Almost all of the few mitochondria that are present in the PMN sediment in a denser fraction during the lysosome isolation. Furthermore, concentrations of sodium azide and antimycin $\mathrm{A}$, which completely inhibit mitochondrial electron transport and $\mathrm{Ca}^{++}$ pump activity, have no effect on the ATP-dependent uptake of $\mathrm{Ca}^{++}$by lysosomes $(13,22)$. ER, which has an energydependent $\mathrm{Ca}^{++}$uptake pump in several cell types $(14,25)$, is also quite sparse in PMN. Moreover, centrifugation of the lysosome suspension through silicone oil resulted in depletion of $>90 \%$ of these low-density microsomes from the lysosome suspension but had no effect on the ATP-dependent $\mathrm{Ca}^{++}$ uptake activity of the reisolated lysosomes.

A second recently described method was also used to isolate and fractionate PMN lysosomes into the two major granule classes (18). As previously reported, the mitochondrial marker cytochrome $c$ oxidase was not present in the $\alpha$ - or $\beta$ bands recovered from the discontinuous Percoll gradient. Although activity of the nonlatent ER marker enzyme, sulfatase $\mathrm{C}$, was present in the whole cell cavitate and the lysosomeenriched fraction, no sulfatase $\mathrm{C}$ activity was located in the visible bands from the gradients. In that the density of ER, determined in this buffer system by sedimentation in Percoll gradients, is $\sim 1.06$, and the mean density of azurophil and specific granules is 1.13 and 1.09 , respectively (26), it would be predicted that the small amount of ER would sediment above the $B$ band. Despite this anticipation, a layer of organelles sedimenting to this density was not observed in these Percoll gradients and could not be detected by spectrophotometric monitoring of the optical density of the gradient fractions in the original report (18). This is not surprising in that ER is very sparse in PMN and in that the total sulfatase $C$ activity in the cavitated PMN was $<2 \%$ of the activity in cultured macrophages (19) and $<1 \%$ of the activity in hepatocytes (27). Although ER was removed from the unfractionated lysosome suspension by passage over the Percoll gradients, ATP-dependent $\mathrm{Ca}^{++}$uptake activity was present in both $\alpha$ - and $\beta$ granules. These data indicate that both azurophil and specific granules contain an active $\mathrm{Ca}^{++}$uptake pump. Further study will be required to determine whether these pumps differ in their kinetic and functional behavior.

The role of this $\mathrm{Ca}^{++}$pump in PMN function requires considerable further study. However, several recent observations suggest that it may have a major influence on cytoplasmic $\mathrm{Ca}^{++}$homeostasis, which influences each of the functional responses of PMN. We and others have demonstrated that the acute rise in cytosolic free $\mathrm{Ca}^{++}$that follows PMN activation with some soluble stimuli (e.g., the chemotactic peptide, FMLP) results from both extracellular and intracellular stores of $\mathrm{Ca}^{++}$ $(2,6,28)$. The inhibitory effect of FMLP on ATP-dependent $\mathrm{Ca}^{++}$uptake by lysosomes could serve to liberate $\mathrm{Ca}^{++}$into the cytosol from this intracellular compartment upon PMN activation. Such a role for the lysosomal $\mathrm{Ca}^{++}$pump being directly related to the chemotactic peptide (or other stimulus) induced $\mathrm{Ca}^{++}$transients would require that the stimulus gain access to the cytosol and interact with the lysosomes rapidly. Although the exact kinetics for reaching the maximum cytosolic $\mathrm{Ca}^{++}$concentration upon stimulation of PMN are unclear (2, 3,6 ), the rise in cytosolic free $\mathrm{Ca}^{++}$begins almost immediately after addition of FMLP. Although it remains to be determined whether FMLP enters the cytosol, it seems unlikely that the peptide could influence the earliest cytosolic $\mathrm{Ca}^{++}$change through a direct interaction with the lysosomal $\mathrm{Ca}^{++}$pump. Whether the more prolonged rise in cytosolic $\mathrm{Ca}^{++}$that follows stimulation with FMLP could be the result of such a direct interaction or whether FMLP-stimulated generation of cytosolic factors, e.g., phosphoinositides $(29,30)$, could rapidly regulate 
the activity of the lysosomal $\mathrm{Ca}^{++}$pump and thereby influence cytosolic $\mathrm{Ca}^{++}$are currently being studied.

The findings that FMLP inhibits ATP-dependent $\mathrm{Ca}^{++}$ uptake by lysosomes and that this inhibition can be blocked by a competitive antagonist of FMLP (BOC-Phe-Leu-Phe-LeuPhe) is consistent with the finding of FMLP mediating its effect by interacting with a receptor on the lysosome surface. Previous studies have demonstrated a specific FMLP receptor on intact PMN lysosomes (principally on specific granules) (31) and, while binding activity was identified on the cytoplasmic surface, these organelles have been proposed as a possible source for the increased number of FMLP receptors expressed on the cell surface after degranulation (32). Whether or not the inhibition of the lysosomal $\mathrm{Ca}^{++}$uptake pump by FMLP is related to the physiologic effects of FMLP on intracellular $\mathrm{Ca}^{++}$homeostasis, this purified peptide should be useful in better defining, and possibly isolating, the lysosomal $\mathrm{Ca}^{++}$pump.

The lysosomal $\mathrm{Ca}^{++}$pump may also serve to down-regulate or turn off activated PMN. This could result from activation of the $\mathrm{Ca}^{++}$uptake pump of intracellular lysosomes by a rise in cytosolic free $\mathrm{Ca}^{++}$. Alternatively, translocation of lysosomal $\mathrm{Ca}^{++}$pumps to the plasma membrane during degranulation should orient these pumps to extrude cytosolic $\mathrm{Ca}^{++}$and thereby decrease the cytoplasmic $\mathrm{Ca}^{++}$concentration. This hypothesis would be consistent with the recent observation by Lagast et al. (33) that plasma membranes isolated from phorbol myristate acetate-stimulated PMN contain a more active $\mathrm{Ca}^{++}$ extrusion pump with an unchanged $K_{\mathrm{m}}$ for $\mathrm{Ca}^{++}$than control plasma membranes (33). Future studies will be directed at examining the regulation of the ATP-dependent $\mathrm{Ca}^{++}$uptake pump of neutrophil lysosomes.

\section{Acknowledgments}

The author gratefully acknowledges the expert technical assistance of Mr. Charles Pollock and Ms. Lorraine Dugoff, Dr. Barbara Styrt and Dr. Ross B. Mikkelsen for valuable discussions and advice, and Ms. Debra Becky for preparation of the manuscript.

This work was supported by grants AI-16732 and AI-22145 from the National Institutes of Health.

\section{References}

1. Smolen, J. E., H. M. Korchak, and G. Weissman. 1981. The roles of extracellular and intracellular calcium in lysosomal enzyme release and superoxide anion generation by human neutrophils. Biochim. Biophys. Acta. 677:512-520.

2. White, J. R., P. H. Naccache, T. F. P. Molski, P. Borgeat, and R. I. Sha'afi. 1983. Direct demonstration of increased intracellular concentration of free calcium in rabbit and human neutrophils following stimulation by chemotactic factor. Biochem. Biophys. Res. Commun. 113:44-50.

3. Pozzan, T., P. D. Lew, C. B. Wollheim, and R. Y. Tsien. 1983. Is cytosolic ionized calcium regulating neutrophil activation? Science (Wash. DC). 221:1413-1415.

4. Yin, H. L., and T. P. Stossel. 1979. Control of cytoplasmic actin gel-sol transformation by gelsolin, a calcium dependent regulatory protein. Nature (Lond.). 281:583-586.
5. Southwick, F. S., and T. P. Stossel. 1983. Contractile proteins in leukocyte function. Semin. Hematol. 20:305-321.

6. Lew, P. D., C. Wollheim, R. A. Seger, and T. Pozzan. 1984. Cytosolic free calcium changes induced by chemotactic peptide in neutrophils from patients with chronic granulomatous disease. Blood. 63:231-233.

7. Ochs, D. L., and P. W. Reed. 1983. ATP-dependent calcium transport in plasma membrane vesicles from neutrophil leukocytes. $J$. Biol. Chem. 258:10116-10122.

8. Volpi, M., Naccache, P. H., and R. I. Sha'afi. 1983. Calcium transport in inside-out membrane vesicles prepared from rabbit neutrophils. J. Biol. Chem. 258:4153-4158.

9. Lagast, H., P. D. Lew, and F. A. Waldvogel. 1984. Adenosine triphosphate dependent calcium pump in the plasma membrane of guinea pig and human neutrophils. J. Clin. Invest. 73:107-115.

10. Lew, P. D., and T. P. Stossel. 1980. Calcium transport by macrophage plasma membranes. J. Biol. Chem. 255:5841-5846.

11. Vincenzi, F. F., E. S. Adunyah, V. Niggli, and E. Carafoli. 1982. Purified red blood cell $\mathrm{Ca}^{2+}$-pump ATPase: Evidence for direct inhibition by presumed anti-calmodulin drugs in the absence of calmodulin. Cell Calcium. 3:545-559.

12. Lehninger, A. L., B. Reynafarje, A. Varcesi, and W. P. Tew. 1978. Transport and accumulation of calcium in mitochondria. Ann. NY Acad. Sci. 307:160-176.

13. Carafoli, E., and M. Crompton. 1978. The regulation of intracellular calcium by mitochondria. Ann. NY Acad. Sci. 307:269284.

14. Moore, L., and I. Pastan. 1978. Energy dependent calcium uptake by fibroblast microsomes. Ann. NY Acad. Sci. 307:177-194.

15. Boyüm, A. 1968. Isolation of mononuclear cells and granulocytes from human blood. Scand. J. Clin. Lab. Invest. 97(Suppl.):77-89.

16. Klempner, M. S., R. B. Mikkelsen, D. H. Corfman, and J. Andre-Schwartz. 1980. Neutrophil plasma membranes. I. High-yield purification of human neutrophil plasma membrane vesicles by nitrogen cavitation and differential centrifugation. J. Cell Biol. 86:21-28.

17. Bradford, M. M. 1976. A rapid and sensitive method for the quantification of microgram quantities of protein utilizing the principle of protein-dye binding. Anal. Biochem. 72:248-254.

18. Borregaard, N., J. M. Heiple, E. R. Simons, and R. A. Clark. 1983. Subcellular localization of the b-cytochrome component of the human neutrophil microbicidal oxidase. Translocation during activation. J. Cell Biol. 97:52-61.

19. Canonico, P. G., H. Beaufay, and M. Nyssens-Jadin. 1978. Analytical fractionation of mouse peritoneal macrophages: Physical and biochemical properties of subcellular organelles from resident (unstimulated) and cultivated cells. J. Reticuloendothel. Soc. 24:115138.

20. Klempner, M. S., and B. Styrt. 1981. Clindamycin uptake by human neutrophils. J. Infect. Dis. 144:472-479.

21. Wallach, D. F., and Kamat, U. B. 1966. Preparation of plasma membrane fragments from mouse ascites tumor cells. Methods Enzymol. 164-172.

22. Thayer, W. S., and E. Rubin. 1982. Antimycin inhibition as a probe of mitochondrial function in isolated rat hepatocytes. Biochim. Biophys. Acta. 721:328-335.

23. Perrin, D. D., and I. G. Sayce. 1967. Computer calculation of equilibrium concentrations in mixtures of metal ions and complexing species. Talanta. 14:833-842.

24. Prentki, M., T. J. Biden, D. Janjic, R. F. Irvine, M. J. Berridge, and C. B. Wolheim. 1984. Rapid mobilization of $\mathrm{Ca}^{2+}$ from rat insulinoma microsomes by inositol-1,4,5-triphosphate. Nature (Lond.). 309:562-564.

25. Hirata, M., T. Hamachi, T. Hashimoto, E. Suematsu, and T. Koga. 1983. $\mathrm{Ca}^{2+}$ release from endoplasmic reticulum of guinea pig peritoneal macrophages. J. Biochem. 94:1155-1163. 
26. Nauseef, W. M., and R. A. Clark. 1985. Separation and analysis of subcellular organelles in a human promyelocytic leukemia cell line, HL60. Clin. Res. 412a.

27. Beaufay, H., A. Amar-Costesec, E. Feytsman, D. ThinesSempoux, M. Wibo, M. Robbi, and J. Berthet. Analytical study of microsomes and isolated subcellular membranes from rat liver. III. Subfraction of the microsomal fraction by isopycnic and differential centrifugation in density gradients. $J$. Cell. Biol. 61:213-221.

28. Klempner, M. S., and P. Johnson. 1984. A link between calcium mobilization and intralysosomal $\mathrm{pH}$ in stimulus-secretion coupling of human neutrophils. Clin. Res. 32:373. (Abstr.)

29. Yano, K., S. Nakashima, and Y. Nozawa. 1983. Coupling of polyphosphoinositide breakdown with calcium efflux in formyl-methionyl-leucyl-phenylalanine stimulated rabbit neutrophils. FEBS (Fed. Eur. Biochem. Soc. Lett. 161:296-300.
30. Volpi, M., R. Yassin, P. H. Naccache, and R. I. Sha'af. 1983. Chemotactic factor causes rapid decreases in phosphatidylinositol,4,5bisphophate and phosphatidylinositol 4-monophosphate in rabbit neutrophils. Biochem. Biophys. Res. Commun. 112:957-964.

31. Fletcher, M. P., and J. I. Gallin. 1983. Human neutrophils contain an intracellular pool of putative receptors for the chemoattractant $N$-formyl-methionyl-leucyl-phenylalanine. Blood. 62:792-799.

32. Fletcher, M. P., B. E. Seligman, and J. I. Gallin. 1982. Correlation of human neutrophil secretion, chemoattractant receptor mobilization and enhanced functional capacity. J. Immunol. 128:941949.

33. Lagast, H., T. Pozzan, F. A. Waldvogel, and P. D. Lew. 1984. Phorbol myristate acetate stimulates ATP-dependent calcium transport by the plasma membrane of neutrophils. J. Clin. Invest. 73:878-883. 